\title{
NeuroD Expression in Podocytes and Interrelationships with Nephrin at Both Nuclear and Cytoplasmic Sites
}

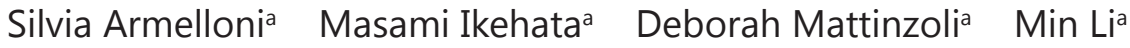 \\ Carlo Maria Alfieric Mariapia Rastaldia, Piergiorgio Messa ${ }^{a, b, c, d}$
}

aRenal Research Laboratory, Fondazione IRCCS Cà Granda Ospedale Maggiore Policlinico, Milan, bUniversity of Study of Milan, Milan, 'Dpt of Nephrology, Urology and Renal Transplant, Fondazione IRCCS Cà Granda Ospedale Maggiore Policlinico, Milan, 'Fondazione D’Amico per la Ricerca sulle Malattie Renali, Milan, Italy

\section{Key Words}

Neurod $\bullet$ Podocytes $\bullet$ Adriamycin nephropaty $\bullet$ Nephrin $\bullet$ Cytoskeleton $\bullet$ Transcription factor - Actin

\begin{abstract}
Background/Aims The research of genes implicated in kidney glomerular function, eliciting cell fate program, is always at the forefront in nephrological studies. Several neurological molecules have been recently the object of study not only for their involvement in the central nervous system differentiation but also for their importance in the functionality of other organs and for mature phenotype, as in kidney. NeuroD, in CNS, is related to two functional roles, the early survival and the differentiation. The aim of our study was to ascertain the presence of NeuroD transcription factor in glomeruli and to understand which targets and mechanisms NeuroD controls. Methods: We used immunofluorescence (IF) studies on both human and mice renal tissues and on cultured podocytes to describe NeuroD distribution; then we investigated NeuroD binding to the nephrin promoter region in cultured podocytes by chromatin-immuno-precipitation (ChIP) assay. The overexpression of NeuroD in podocytes was used to establish first its role in nephrin synthesis, evaluated by real-time quantitative (RTq) PCR and western-blot (WB) and successively to determine the recovery of cell morphology after adriamycin injury, measuring foot processes length. Results: We identified NeuroD transcription factor in glomeruli, in the same cells positive for WT1 and synaptopodin, namely podocytes; subsequently we observed a differentiation dependent NeuroD distribution in cultured podocytes, and a consistent link of NeuroD with the Nephrin promoter leading to the regulation of Nephrin translation and transcription. Our data also describes NeuroD expression in cytoplasm as phosphoprotein linked to nephrin and actinin4. Preliminary experiments seem to indicate NeuroD involved in dynamics of cell shape regulation after adriamycin injury. Conclusion: we propose that NeuroD possess in podocytes a dual ability acting in the nucleus as a transcription factor and in cytoplasm stabilizing cell shape.




\section{Cellular Physiology Cell Physiol Biochem 2018;46:873-889

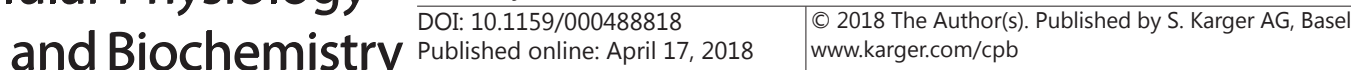 \\ Armelloni et al.: NeuroD Expression in Podocytes and Nephrin Regulation}

\section{Introduction}

Podocytes are highly specialized cells whose primary and secondary processes and their intercellular junctions are fundamental to maintain the glomerular structure and function; defect in their number, in actin cytoskeleton rearrangement and/or in the related alteration of the podocyte shape are observed in response to injury [1,2]. Maturation of podocytes is a complex dynamic process involving several transcriptional factors (TFs), such as Pax2, WT1, Pod1, Lmx1b, Maf1, Sp1, NFkB and others; they are described to be responsible, in specific stages of glomerular development and maturation, for the expression of molecules leading to foot process assembly, structural organization of the slit diaphragm or cytoskeletal interaction [3-7].. The expression of these TFs or their downregulation control the activation of genes responsible for the expression of the specific characteristics of the differentiated podocytes.

Previous studies have pointed out the presence in podocytes of the same machinery adopted by neurons for processes formation accompanied, at the slit diaphragm level, by a multitude of receptors and signalling molecules [8-11]; moreover mutations in some of these protein lead to proteinuria eventually resulting in focal segmental glomerular sclerosis (FSGS) $[12,13]$.

A key actor of the slit diaphragm is nephrin, a cell adhesion molecule responsible for the stability and for the regulation of the signalling in podocytes and also described in several areas of the central nervous system (CNS) at the synaptic cleft of neuronal cells [14]; nephrin exerts a functional role of signal transduction finally converging on the dynamic of actin cytoskeleton, essential for maintaining shape and function of podocytes. Branching and elongation of foot processes are mechanisms necessary to create the flexible and proper apparatus able to respond to chemical and mechanical stimuli originating from the blood stream and urinary space, to which podocytes constantly counteract $[15,16]$.

Among the many systems involved in neuron physiopathology, neurogenins and neurogenic differentiation factor 1 (NeuroD or NeuroD1) (UniProt ID: Q13562) proteins have been the object of intense investigation [17]. Both proteins have been found to be closely expressed in mice and in Xenopus, where they have regulatory activity on the development of the nervous system, and promote the formation of pancreatic islets from the endocrine cell progenitors [18]. NeuroD plays a crucial role in early and terminal differentiation of the granule neurons in hippocampus and cerebellum, in dendrite morphogenesis and in the maintenance of the cerebellar cortex, inducing tens of genes regulating transcription, cytoskeleton remodelling and signal transduction [17, 19, 20, 21]. Furthermore, NeuroD expression has been demonstrated in a number of different organs and tissues, [22, 23] and its mutations have been described to be associated with a number of diseases of these organs [24]. NeuroD belongs to the family of basic helix-loop-helix transcription factors, like Pod1 whose earlier deletion arrests podocytes differentiation [25].

The first aim of the present study was to explore if NeuroD is expressed also in the kidney and in particular in the podocytes. Since we found that NeuroD is in fact expressed in podocytes, both in the cytoplasm and nucleus, we also investigated if NeuroD may be involved in gene regulation and cellular function of these cells.

\section{Materials and Methods}

\section{Renal tissue samples}

Normal renal tissue was derived from patients submitted to nephrectomy for renal neoplasia and who gave informed consent to the examination of the removed renal tissue (M.04.NUTRAR.CONS), and from normal mice kidneys, obtained from 3month-old C57BL/6 or BALB/c/Pas inbred strain animals (Charles River Laboratories, Calco, Lecco, Italy) according to the Protocol N. 07/13 approved by the Milan University Institutional Care and Ethical Treatment Committee, sacrificed after anesthesia induced by intraperitoneal injection of $370 \mathrm{mg} / \mathrm{Kg}$ of chloral hydrate. The tissues were embedded in TissueTek OCT compound (Sakura, Finetek, Japan), snap-frozen in a mixture of isopentane and dry-ice, and stored at $-80^{\circ} \mathrm{C}$. 


\section{Cellular Physiology Cell Physiol Biochem 2018;46:873-889 \begin{tabular}{ll|l} 
and Biochemistry Published online: April 17, 2018 & $\begin{array}{l}\text { C } 2018 \text { The Author(s). Published by S. Karger AG, Basel } \\
\text { www.karger.com/cpb }\end{array}$
\end{tabular} \\ Armelloni et al.: NeuroD Expression in Podocytes and Nephrin Regulation}

\section{Podocytes cell cultures}

We studied conditionally immortalized podocytes SV1 (SV1) from transgenic $H$-2Kb-tsA58 mice (CLS, Eppelheim Germany), previously propagated at $33^{\circ} \mathrm{C}\left(\operatorname{Imm} 33^{\circ} \mathrm{C}\right)$ in DMEM: F12 medium supplemented with $10 \% \mathrm{FCS}, 100 \mathrm{U} / \mathrm{ml}$ penicillin, $100 \mu \mathrm{g} / \mathrm{ml}$ streptomycin, $2 \mathrm{mM} \mathrm{L}$-glutamine and $20 \mathrm{U} / \mathrm{ml}$ recombinant mouse $\gamma$ interferon (all from Sigma Aldrich, Milan, Italy) and subsequently grown with the complete medium, without $\gamma$ interferon, in culture flasks (Corning, Milan, Italy) precoated with collagen type IV and thermoshifted to $37^{\circ} \mathrm{C}$ for differentiation for 7 days $\left(\operatorname{Imm} 37^{\circ} \mathrm{C}\right)$.

We also studied primary cultures podocytes derived from C57BL6/J mice (C57BL/6), obtained by sieving as previously described [8], according to the current ethical and legislative rules Directive 2010/63/ EU for animal experiment, and seeded at second passage at $37^{\circ} \mathrm{C}$ in $5 \% \mathrm{CO} 2$ atmosphere, with complete medium composed of DMEM: F12 medium supplemented with $10 \% \mathrm{FCS}, 5 \mu \mathrm{g} / \mathrm{ml}$ human apo-transferrin, 10 ${ }^{7} \mathrm{M}$ hydrocortisone, $5 \mathrm{ng} / \mathrm{ml}$ sodium selenite, $0.12 \mathrm{U} / \mathrm{ml}$ insulin, $100 \mathrm{U} / \mathrm{ml}$ penicillin, $100 \mu \mathrm{g} / \mathrm{ml}$ streptomycin, $2 \mathrm{mM}$ L-glutamine (all reagents from Sigma-Aldrich).

\section{Neuro2a cells}

Mouse neuroblastoma cells Neuro2a (Neuro2a) (ATCC $®$ CCL131 ${ }^{\text {TM }}$ ) were used as positive control of NeuroD expression both in immunofluorescence studies and in Western Blot [26]. The cells were seeded in

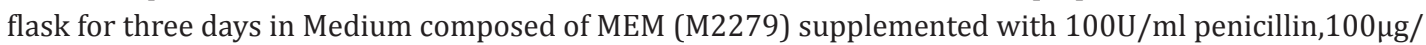
$\mathrm{ml}$ streptomycin, $2 \mathrm{mM}$ L-glutamine, 10\% FBS, 1mM Sodium Pyruvate, NEAA solution (all from Sigma Aldrich, Milan, Italy); subsequently the medium was replaced with Neurobasal medium (21103 Gibco) supplemented with B27 (17504 Gibco), 100U/ml penicillin,100 $\mathrm{gg} / \mathrm{ml}$ streptomycin and $2 \mathrm{mM}$ L-glutamine, $10 \%$ and the differentiation was evaluated for the appearance of neurites.

\section{Glomerular endothelial cells}

Conditionally immortalized human glomerular endothelial cells (hGEnC) (CiGEnC, University of Bristol, Bristol, UK) were grown, for propagation at $33^{\circ} \mathrm{C}$, in endothelial growth medium 2-microvascular (EGM2-MV, Lonza, Walkersville, MD USA) containing EBM ${ }^{\mathrm{TM}}-2$ Basal Medium, $5 \%$ fetal bovine serum (FBS), Gentamicin/Amphotericin-B [GA], Hydrocortisone, Fibroblast Growth Factor-Beta [hFGF-b], Insulin-like Growth Factor [R3-IGF-1] and Ascorbic Acid as supplied, but excluding Vascular Endothelial Growth Factor [VEGF]. For experiments, cells were transferred to $37^{\circ} \mathrm{C}$ to stop the growth, for at least 3 days.

\section{Cell damage model}

To induce podocyte damage Adriamycin Nephropathy (AN), characterized in rodents by histological changes resembling those of human chronic proteinuric renal disease, was applied; this model, that in animals results in focal glomerulosclerosis, in vitro leads to podocyte cell processes shortening, cytoskeletal actin remodeling and rounding of the cell shape and was induced by $0.8 \mu \mathrm{M}$ adriamycin (adria) (doxorubicin hydrochloride, Sigma-Aldrich) dissolved in medium for 24 hours. After this time the solution was removed and replaced by medium; four groups of cells were treated in different ways: control, adriamycin 24 hours, adriamycin 24 hours followed by NeuroD over expression for 48 hours, and NeuroD over expression only, for 48 hours. All cells were fixed at the same time, after 48 hours from removal of adria, with cold $4 \%$ paraformaldehyde (PFA) for 10 minutes and acetone for 5 minutes for the staining of cytoskeleton by alpha actinin and for the nuclear and cytoplasmic staining of NeuroD. Podocytes processes length was measured after alpha actinin staining on 40x images acquired by Zeiss Axioscope 40FL microscope (Carl Zeiss SpA, Arese, Milano, Italy), and calculated by AxioVision Rel.4.8 software (Carl Zeiss) on 54, 69, 53 and 45 cells of respectively control, over NeuroD, adria and adria+ over NeuroD group; nuclear or cytoplasmic fluorescence intensity was measured on 47,54,35, and 62 cells of respectively control, over NeuroD, adria and adria+ over NeuroD group, as densitometric mean by the same software.

\section{Immunofluorescence studies}

Immunofluorescence was performed using standard procedures. Four micrometer sections of mice and human tissues were placed on slides and fixed in cold 4\% PFA and/or acetone for 10 or 5 minutes respectively. Cultured mice podocytes, Neuro-2a and hGEnC grown on Thermanox coverslips (Nunc, VWR Int., Milan, Italy) were fixed in the same way. After fixation the following primary antibodies (Ab) were used for indirect immunofluorescence studies: rabbit anti NeuroD1 (ab-16508) (Abcam, Milano, Italy) 1:50, 


\section{Cellular Physiology Cell Physiol Biochem 2018;46:873-889 and Biochemistry Published online: April 17, $2018 \quad \begin{aligned} & \text { DOI: 10.1159/000488818 } 2018 \text { The Author(s). Published by S. Karger AG, Basel } \\ & \text { www.karger.com/cpb }\end{aligned}$ \\ Armelloni et al.: NeuroD Expression in Podocytes and Nephrin Regulation}

mouse anti synaptopodin (65194) (Progen, Heidelberg, Germany) 1:20, goat antiWT1 (sc-15421) (St Cruz Biotechnology, Heidelberg, Germany)1:50, mouse antiCD31 (ab9498) (Abcam) 1:20, mouse anti alpha SMA (ab7817) (Abcam)1:200; rabbit anti alpha actinin (sc15335) (St Cruz); rabbit anti alpha actinin4 (0042-05) (Immunoglobe, Himmelstadt, Germany) after washing the appropriate secondary Alexa Fluor (Invitrogen, Milano, Italy) antibodies were sequentially applied: 546 goat anti rabbit IgG (A11035), 488 goat anti mouse IgG (A11029), 488 rabbit anti goat IgG (A11078), 488 goat anti rat IgG (A11006) all diluted 1:70; DAPI (Sigma-Aldrich) nuclear staining was added with the secondary antibody. Specificity of Ab labeling was demonstrated by the lack of staining after substituting control immunoglobulins for the primary antibodies. For cell culture staining the antibodies addition was preceded by permeabilization with $0.3 \%$ TritonX-100 and blocking reagent was used to prevent unspecific binding. Slides were mounted with Fluorsave aqueous mounting medium (Merk, Milano, Italy). Images were acquired by Zeiss Axioscope 40FL microscope (Carl Zeiss), equipped with AxioCamMRc5 digital videocamera and immunofluorescence apparatus, and recorded by AxioVision software 4.8, or by Zeiss AxioObserver microscope equipped with high resolution digital videocamera AxioCam and Apotome system (Carl Zeiss) for structured illumination.

\section{Proximity Ligation Assay (PLA)}

Duolink (Olink Bioscience, Uppsala, Sweden) in situ experiment was performed according to the user manual. The cells were fixed with acetone or PFA and the following primary antibodies were used: goat NeuroD (N19) (sc1084) (Santa Cruz), rabbit antiWT1 (ab15249) (Abcam), rabbit anti podocin (P0372) (Sigma-Aldrich), rabbit anti nestin (N1602) (18741) (IBL International, Tecan, Hamburg, Germany) rabbit anti actinin4 (0042-05) (Immunoglobe). Secondary antibodies conjugated with oligonucleotides (PLA probe MINUS and PLA probe PLUS) were added. The ligation and the amplification reagents permitted to the signal to be analyzed as a distinct red fluorescent spot by fluorescence microscopy. DAPI (Sigma-Aldrich) nuclear staining was added before mounting the slides.

\section{Chromatin Immunoprecipitation (ChIP)}

Chromatin Immunoprecipitation was performed by Pierce Agarose ChIP Kit (Pierce, Thermo Fisher Scientific, Monza, Italy).Briefly, podocytes subcultured on T75 flask in triplicate, at a density of $2 \times 10^{6}$ cells were cross-linked with $1 \%$ formaldehyde for 10 minutes at room temperature before adding glycine solution to stop the reaction. Cell lysis was followed by Micrococcal nuclease digestion, $1 \mathrm{U} / \mu \mathrm{l}$ for 15 minutes at $37^{\circ} \mathrm{C}$ with production of $100-400 \mathrm{bp}$ DNA fragments, as observed after $2 \%$ agarose gel electrophoresis and a portion of total cross-linked lysate was saved for successive analysis (INPUT). Immunoprecipitation was obtained by incubating overnight at $4^{\circ} \mathrm{C}$ the sheared chromatin with $10 \mu \mathrm{g}$ of NeuroD (G20) X antibody for ChIP applications (SantaCruz), or with Normal rabbit IgG as negative control (Pierce), followed by incubation with $20 \mu \mathrm{l}$ of ChIP Grade Protein A/G Agarose (Pierce) for 1 hour at $4^{\circ} \mathrm{C}$ on rocking platform. The total nuclear unlinked extract (unlinked) was kept for Western Blot (WB) evaluation; the subsequent IP elution and DNA recovery, collected for both WB and PCR analysis, followed standard instructions. The concentrations of DNA from INPUT, and from ChIP were calculated after proteinase K treatment by spectrophotometric determination.

\section{Co-Immunoprecipitation (IP)}

Two immunoprecipitations were performed by Classic IP Kit (Pierce), the first to detect the proteins linked to NeuroD and the second to identify the proteins bound to nephrin. According to the manufacturer's instructions, the immune-complexes were obtained combining $10 \mu \mathrm{g}$ of affinity purified antibody to NeuroD (sc-1086) or to Nephrin (sc-28192) (both Santa Cruz) with the pre-cleared cell lysate. The elution from Protein A/G Agarose was in reducing condition with the addition of dithiothreitol (DTT) to a final concentration of $20 \mathrm{mM}$. The immune-complexes were directly used for WB.

\section{Western Blot (WB)}

Cytoplasmic proteins were extracted with complete Lysis M solution (Roche, Mannheim, Germany) from control podocytes, from NeuroD over-expressed or silenced podocytes , 24 and $48 \mathrm{hrs}$ after transfection, and from Neuro-2a and hGEnC used as positive and negative control respectively; for nuclear lysate $\mathrm{NaCl}$ at final concentration of $0.5 \mathrm{M}$ was added to the same Lysis $\mathrm{M}$ solution; protein concentration was determined by DC Protein Assay (BioRad Laboratories Inc., CA, USA) similar to the Lowry assay. Proteins (10-15 $\mu \mathrm{g})$ 


\section{Cellular Physiology Cell Physiol Biochem 2018;46:873-889 \begin{tabular}{c|c|c|} 
DOI: 10.1159/000488818 & O 2018 The Author(s). Published by S. Karger AG, Basel \\
www.karger.com/cpb
\end{tabular} \\ Armelloni et al.: NeuroD Expression in Podocytes and Nephrin Regulation}

or immunoprecipitate complex diluted in reducing sample buffer, were separated on 8 or 10\% SDS polyacryalmide gel and blotted on ImmunBlot PVDF membrane (BioRad). After blocking, each membrane was incubated with the primary antibody, followed by the proper horseradish peroxidase-conjugated (HRP) secondary antibody, and positive reaction products were detected by BM Chemiluminescence Western Blotting Kit (Roche, Milano, Italy). Images were digitally acquired by Chemidoc XRS instrument (Bio-Rad). The following primary antibodies were used for the study: goat anti-neurod (sc1086) (Santa Cruz), goat antineurod (sc1084) (Santa Cruz), rabbit anti neurod (ab16508) (Abcam), Rabbit anti neurod (Ser 274) phospho specific (TA312014) (Origene, Bologna, Italy) guinea pig anti-nephrin (GP-N2) (Progen), rabbit anti-alphaactinin (sc15335) (Santa Cruz), rabbit anti-cofilin (5175) (Cell Signaling, Euro Clone, Milano, Italy), rabbit anti-histone H3 (ab1791) (Abcam), mouse anti-alpha-tubulin (ab7291) (Abcam), followed by proper HRP conjugated secondary antibody: anti mouse-rabbit-HRP conjugated (by BM Chemiluminescence Western Blotting kit, Roche), anti guinea pig-HRP (ab6771) (Abcam), anti goat-HRP (ab6741) (Abcam). To detect IP VeriBlot secondary antibodies (HRP) were used: anti-goat IgG (ab157532), anti- IgG (ab131366) (Abcam). These antibodies recognize native (non-reduced) antibodies and therefore the detection of heavy (50 kDa) and light chains $(25 \mathrm{kDa})$ is minimized, if the immunoprecipitate is fully reduced. All of the cytoplasmic protein bands were normalized for the actinin or tubulin level and the nuclear proteins bands for H3 histone level. Negative controls were performed by loading buffer instead of proteins. Positive controls were performed using a brain protein extract. Protein bands were detected by BM Chemiluminescence Western Blotting Kit (Roche) and analyzed for semi-quantitative analysis of density by ChemiDoc XRS+ with Image Lab Software (Bio Rad) and for molecular weight determination.

\section{Transfections}

Podocytes subcultured in 6 well plate at semiconfluence with medium devoid of penicillin and streptomycin, were transiently transfected with Lipofectamine 2000 (Invitrogen) in serum reduced medium OptiMEM (Gibco, Thermofisher, Rodano, Milano, Italy) following manufacturer's instruction; for Neurod1 overexpression 2, $5 \mu \mathrm{g}$ of Myc-DDK- tagged ORF clone of Mus musculus Neurogenic differentiation1 (NeuroD1) as transfection ready DNA (MR205460, Origene) was added and for cells knockdown two sets of 200pmol target specific duplex Mission SiRNA oligos for mouse NeuroD1, (SASIMm01_00082459, SASIMm02_00319605) (Sigma-Aldrich) were used; Mission SiRNA Universal scrambled RNA duplexes were used as negative controls.For promoter activation experiments podocytes were simultaneously transfected with $1 \mu \mathrm{g}$ of GlucON Nephrin or Kirrel2 mouse promoter clone dual-reporter vector systems (MPRM12209PG04 and MPRM11692-PG04) (Genecopoeia, Milano, Italy). The medium was changed 8 hours later with complete growth medium. The supernatant was collected 24- 48 and 72 hours post transfection and proteins and RNA were extracted at the same times.

\section{$P C R$}

PCR for Nephrin promoter was performed after ChIP with $5 \mu \mathrm{g}$ of DNA and the following Thermal Cycler conditions: initial denaturation: $8^{\prime}$ at $95^{\circ} \mathrm{C}$; variable cycles x 12 : denaturation $35^{\prime \prime}$ at $95^{\circ} \mathrm{C}$, annealing $35^{\prime \prime}$ at $60^{\circ} \mathrm{C}$ for 2 cycles $59,5^{\circ} \mathrm{C}$ for 2 cycles, $59^{\circ} \mathrm{C}$ for 2 cycles, $58,5^{\circ} \mathrm{C}$ for 2 cycles $58^{\circ} \mathrm{C}$ for 2 cycles, $57,5^{\circ} \mathrm{C}$ for 2 cycles; extension $50^{\prime \prime}$ at $72^{\circ} \mathrm{C}$. Constant cycles x 23 , denaturation $35^{\prime \prime}$ at $95^{\circ} \mathrm{C}$, annealing $35^{\prime \prime}$ at $57^{\circ} \mathrm{C}$, extension $50^{\prime \prime}$ at $72^{\circ} \mathrm{C}$, Final extension $9^{\prime}$ at $72^{\circ} \mathrm{C}$. Primers sequences $5^{\prime}-3^{\prime}$ were selected within mouse Nephrin promoter sequence on chromosome7 (TRED ID: 76481, TSS 22066787) obtained by Transcriptional Regulatory Element Database (TRED) (Cold Spring Harbor Laboratory) and were: Nephrin promoter forward 5' GTG GTG GAG TTG AGC CAG TT 3'; Nephrin promoter reverse 5'GGC CAA GGT GTA GAG CTG CTG TC3'. The presence of the $468 \mathrm{bp}$ amplicon was detected on $2 \%$ agarose by gel analysis, relative to low DNA mass ladder control (Invitrogen).

\section{Luciferase Reporter Assays}

The levels of secreted reporter proteins, Gaussia Luciferase (Gluc) and Secreted Alkaline Phosphatase (SEAP) in medium, were measured by Secrete-Pair Dual Luminescence Assay Kit (Genecopoeia). GLuc and SEAP intensity, expressed in count per second, were measured by luminometer (Xenius Safas, Monaco) following the protocol for Enhanced Signal Stability and SEAP Assay Procedure, as indicated in the manual: $10 \mu \mathrm{l}$ of the supernatant were added in white opaque 96 well plate in triplicates and luminescence signal was measured with 1 second of integration. GLuc activity was normalized by SEAP luminescence, 


\section{Cellular Physiology Cell Physiol Biochem 2018;46:873-889 \begin{tabular}{ll|l} 
and Biochemistry Published online: April 17, 2018 & $\begin{array}{l}\text { C } 2018 \text { The Author(s). Published by S. Karger AG, Basel } \\
\text { www.karger.com/cpb }\end{array}$
\end{tabular} \\ Armelloni et al.: NeuroD Expression in Podocytes and Nephrin Regulation}

relative to cell number. Calculated ratio of GLuc over SEAP intensity was compared. Activation was estimated in treated cells relative to control podocytes and represented as fold induction. The values are means \pm SD from at least three independent experiments performed in triplicates.

RNA extraction and quantitative RTqPCR

Total RNA was purified from undifferentiated and mature podocytes and after 24 and $48 \mathrm{hrs}$ of NeuroD and Kirrel2 over-expression or silencing, using Aurum total RNA mini kit (BioRad) free of contaminating genomic DNA and the cDNA was produced from $500 \mu$ g of RNA by iScript cDNA Syntesis Kit (BioRad). The quantitative PCR (RTqPCR) was performed using iQ Sybr green Supermix (BioRad) and run with CFX Connect RealTime System provided with CFX Manager Software for data acquisition and analysis. Primers for mouse Neurod1, Nephrin, Kirrel2, and Rpl13, to normalize gene expression, were purchased from IDT. The following primers were used: NeuroD1 forward 5'ACC TTG CTA CTC CAA GAC CCA GAA 3' and reverse 5'TTT GCA GAG CGT CTG TAC GAA GGA3'; Nephrin forward 5' CCT CTT CAA ATG CAC AGC CAC CAA 3' and reverse 5'ACC TGA TTT GGA ACC TCT GAG GCA 3'; Kirrel2 forward 5'GCG AGG GCA GGT TAT CTT AC3', reverse 5' GGG AGT TCC AGA GCT CAA TTC3'; Rpl13 forward 5' GTG AGG TGC CCT ACA GTG AGA TAC3' and reverse 5'GAT GGT GCG AGC CAC TTT CTTG 3'. Data are expresses as normalized expression relative to control podocytes.

\section{Statistical analyses}

Data are presented as mean \pm SD. At least three replicates were conducted for each in vitro experiment. Two-tail Student's t test was used for analysis when two groups of data were compared and to predict the significance level of $* \mathrm{p}<0.05, * * \mathrm{p}<0.01$ or $* * * \mathrm{p}<0.001$.

\section{Results}

\section{Identification of NeuroD in the glomerulus}

The IF studies on both human and mice renal tissues demonstrated the presence of both glomerular and tubular positivity. Given that the main aim of our research was to explore the possible expression of NeuroD in podocytes, we decided to focus on glomerular NeuroD expression only. In fact, NeuroD was expressed only in the podocytes, both in the cytoplasm and nucleus, as demonstrated by the colocalization with synaptopodin (Fig. 1A) and WT1 (Fig. 1B), which are well recognized markers of mainly cytoplasm and nucleus of podocyte, respectively. No NeuroD IF positivity was found in the endothelial cells or mesangial cells, marked with CD31 (Fig. 1C) and alpha SMA (Fig. 1D), respectively.

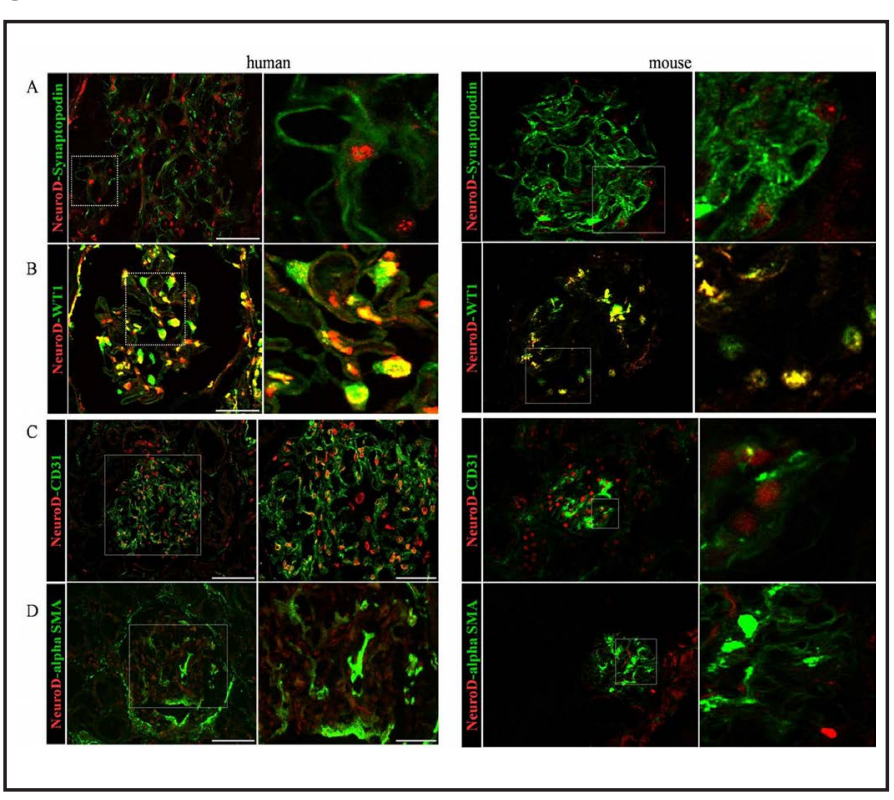

Fig. 1. Expression of NeuroD in the normal human glomerulus. NeuroD double labeling in human and mouse kidney sections. NeuroD (red) with podocyte marker synaptopodin (A) marks the same cells, lining the capillary wall and with WT1(B) (green) exhibits a nuclear colocalization (yellow); a mild staining is visible on tubuli. Endothelial cells marker CD31(C) and mesangial cell marker alpha-smooth muscle actin (alpha-SMA) (D) (green) show the staining of different cell types (Scale bar $50 \mu \mathrm{m}$ ). 


\section{Cellular Physiology Cell Physiol Biochem 2018;46:873-889

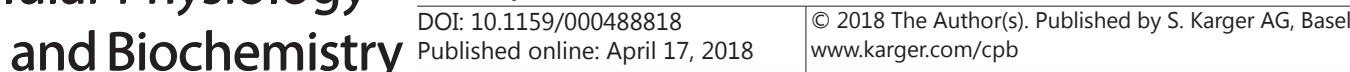

\section{Characterization of NeuroD expression in mice podocytes}

NeuroD was also present in podocytes obtained from both C57BL6 mice and from SV1 cell line, at both nuclear and cytoplasmic level and also in the foot processes (Fig. 2A).

Neuro-2a were used as positive control of NeuroD staining because this cell line is known to express Neurod1 [26] and hGEnC as negative control as observed in renal tissues; in fact after PFA fixation, Neuro2 a cells nuclear positivity was unequivocally found by contrast to human endothelial cells.(Fig. 2D) Nuclear signal positivity of NeuroD was supported by colocalization with DAPI and WT1 (Fig. 2B), detected also by PLA (Fig. 2C), highlighting not only the nearness but also the possible strict functional connection between the two transcription factors: the red spots are mostly in the nuclei of podocytes and to a lesser extent on the cell body.

The presence of NeuroD in the nuclear and in the cytosolic fractions of podocytes and Neuro-2a cells (Fig. 3D) was also investigated by WB using antibodies which recognize different regions of NeuroD,

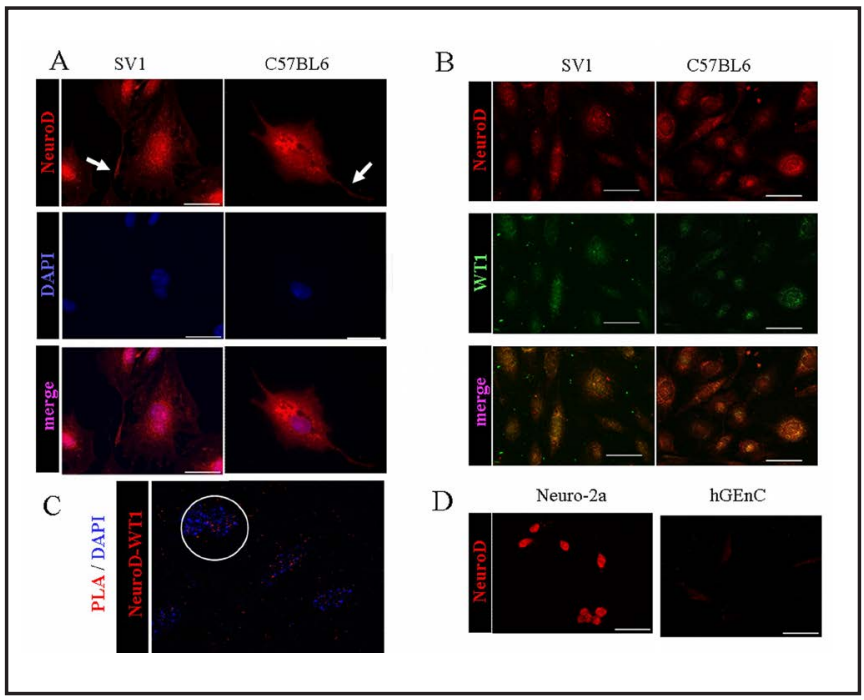

Fig. 2. Neurod1 in culture of mouse podocytes. The presence of NeuroD in podocytes was assessed by IF staining of cultured differentiated SV1 cells and of primary podocytes outgrowing from C57BL6 mouse glomeruli (A-B). NeuroD is evidenced in nucleus and cytoplasm and is also clearly expressed in the foot processes (A) (arrows). NeuroD (red) co-localizes in the nucleus with DAPI (blue) and WT1 and the NeuroD proximity with podocyte marker WT1 is confirmed by PLA (red spots) mainly in the nucleus ( C).(Scale bar $50 \mu \mathrm{m}$ ). (D) Neuro-2a cells were used as NeuroD positive control, hGEnC as negative control.

Fig. 3. Nuclear and cytoplasmic expression of NeuroD in podocytes. Western blot were performed to determine nuclear (nl) and cytoplasmic (cyt) presence of NeuroD in lysate of mature podocytes, using antibodies recognizing $\mathrm{N}$-terminal domain, C-terminal domain (A) or residues 100-200 common to human and mouse NeuroD (B); the signal detected reveals three bands, of which the more represented is the $45 \mathrm{kD}(\mathrm{A})$, or a single lane (B). The molecular mass distribution of NeuroD, from 5 experiments, was calculated (A-B). To confirm the presence of NeuroD in nuclear lysate we also detected

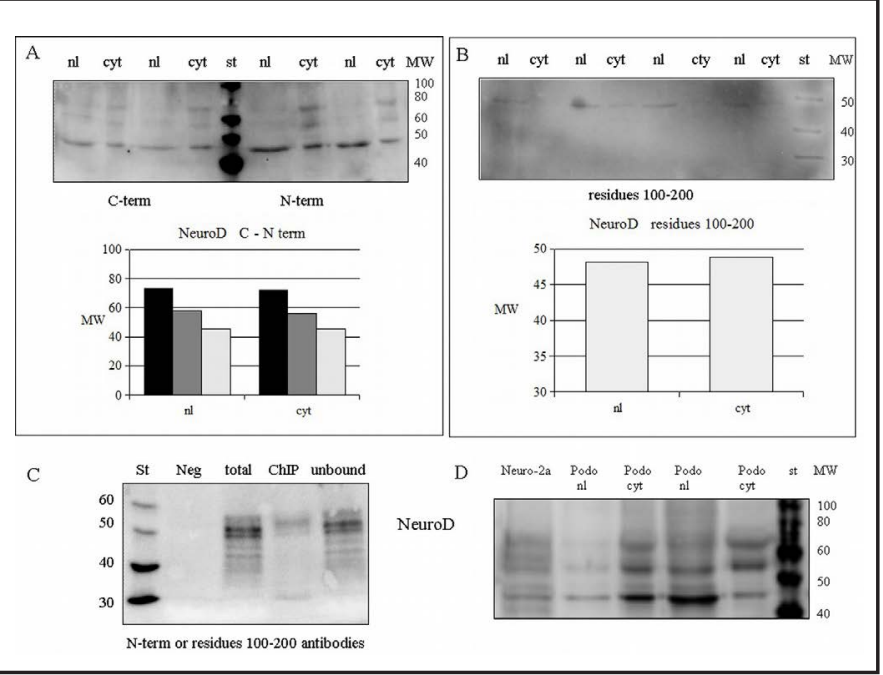
NeuroD by WB in samples obtained by IP: total nuclear fraction, nuclear fraction linked to chromatin (ChIP obtained with antibody against C-terminal domain) and nuclear fraction not bound to DNA; the results were obtained using antibodies against N-terminal domain or against epitope of residues $100-200$ (C). Neuro-2a cells were used as positive control (D). 


\section{Cellular Physiology Cell Physiol Biochem 2018;46:873-889

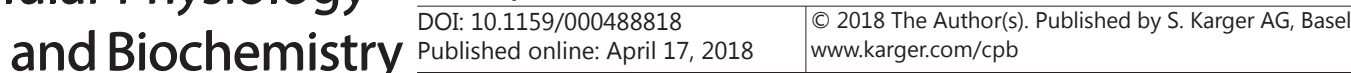

Fig. 4. Differentiation dependent NeuroD distribution. SV1podocytes maintained in undifferentiated status were cultured at $33^{\circ} \mathrm{C}$ and induced with gamma interferon $\left(\operatorname{Imm~} 33^{\circ} \mathrm{C}\right)$ or were induced to differentiate at $37^{\circ} \mathrm{C}$ in complete growth medium for 7 days (Imm $37^{\circ} \mathrm{C}$ ). NeuroD staining was performed and analyzed at these two time points by IF (red) (A) (Scale bar $50 \mu \mathrm{m}$ ). The increase and the distribution of NeuroD was assessed comparing the mean density of the fluorescence into the nucleus and in the cytoplasm from at least 40cells for each group (B) and Student $t$ Test was used to evaluate
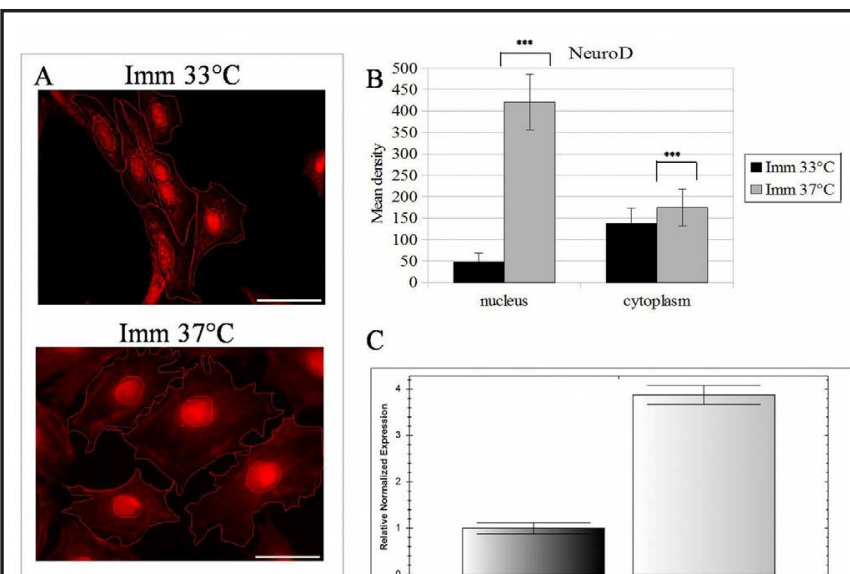

C

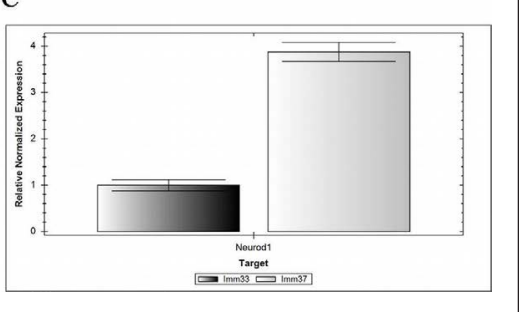
its significance $\left({ }^{* * *} \mathrm{p}<0.001\right)$. RTqPCR

analysis of NeuroD mRNA obtained from Imm $33^{\circ} \mathrm{C}$ and $\operatorname{Imm} 37^{\circ} \mathrm{C}$ was also performed and confirms an increased expression in differentiated cells (C).

common to mouse and human protein sequences. The Mass of the protein is 39.92 $\mathrm{kD}$ but when antibodies directed against C or N-terminal domains were used, three distinct bands, with apparent molecular mass of $45.4 \pm 13.9,57.1 \pm 17.4$ and 72.7 $\pm 2.13 \mathrm{kD}$ respectively, were detected in cytosolic and, at a lesser extent, in nuclear lysates (Fig. 3A), with the lowest MW band being the most abundantly expressed. At variance, a single lane was observed when an antibody selectively directed to an intermediate epitope of the protein was used (Fig. 3B); this fraction has a MW (48 kD) very close to that of the most represented band by the $\mathrm{C}$ or $\mathrm{N}$-terminal antibodies. The nuclear specificity of NeuroD presence and the accuracy of the molecular weight was verified by WB in samples obtained by IP with NeuroD antibody, in both the enriched

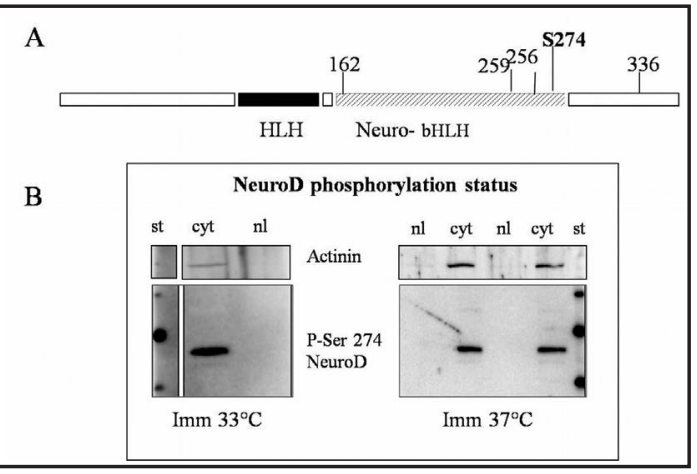

Fig. 5. Regulation of NeuroD phosphorylation Representation of NeuroD phosphorylation sites. (A) NeuroD presence as a phosphoprotein around the phosphorylation site of serine 274 (P-L-SP$\mathrm{P}-\mathrm{P})$ was evaluated in undifferentiated (Imm $33^{\circ} \mathrm{C}$ ) and mature (Imm $37^{\circ} \mathrm{C}$ ) podocytes (B). NeuroD is phosphorylated almost exclusively in the cytoplasm (cyt). nuclear fraction, where the DNA-linked and unlinked NeuroD are expected to be present, and in the ChIP fraction, where only the DNA-linked NeuroD should be represented.

These experiments confirmed the presence of NeuroD in the podocyte nucleus as a band of approximately $50 \mathrm{kD}$, with a consistent part of it being linked to DNA (Fig. 3C).

\section{Differentiation dependent NeuroD distribution}

When we studied NeuroD expression at different stages of podocyte maturation, by fluorescence semi-quantitative analysis (Fig. 4A), the immunostaining revealed that NeuroD is expressed also in immature cells. However, NeuroD expression increased in more differentiated podocytes, particularly in the nuclear fraction $47.8 \pm 20.9$ vs $420.5 \pm$ $\left.64.9{ }^{* * *} \mathrm{p}<0.001\right)$ but also in cytoplasm $\left.137.1 \pm 35.6 v s 174.2 \pm 42.6{ }^{* * *} \mathrm{p}<0.001\right)$ (Fig. 4B). An increased protein synthesis was also suggested by the 3-4-fold rise in mRNA of mature podocytes as compared with immature cells (Fig. 4C).

\section{KARGER}




\section{Cellular Physiology Cell Physiol Biochem 2018;46:873-889 and Biochemistry Published online: April17, $2018 \quad \begin{aligned} & \text { DOI 1015/2018 The Author(s). Published by S. Karger AG, Basel } \\ & \text { www.karger.com/cpb }\end{aligned}$ \\ Armelloni et al.: NeuroD Expression in Podocytes and Nephrin Regulation}

Fig. 6. NeuroD binding to Nephrin promoter. NeuroD regulatory elements were identified by NSITE in Nephrin promoter region (A) NeuroD binding to chromatin was assessed in podocytes by ChIP assay and subsequently the PCR amplification of Nephrin promoter was performed on total DNA of podocyte, on NeuroD ChIP fraction and on negative control (NC). Amplicon of Nephrin promoter is $468 \mathrm{bp}$ (B). Relative quantification of Nephrin promoter bound to NeuroD (ChIP) or not linked to NeuroD (NeuroD nl) was evaluated on DNA by RTq-PCR (C).

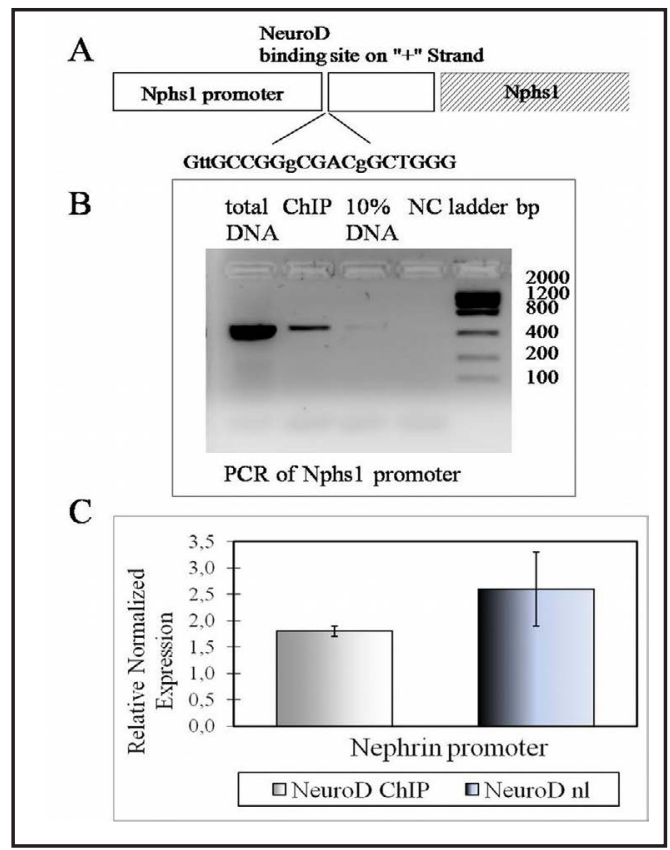

Fig. 7. NeuroD overexpression activates Nephrin promoter. NeuroD was overexpressed or silenced and the maximal outcome was evaluated by RTqPCR 48 or 24 hrs after NeuroD ORF clone transfection or SiRNA oligos addition, respectively (AC). NeuroD translation was monitored by western blot (B-D). The effects of NeuroD variation on nephrin promoter activity, were calculated in primary (WT) or in immortal podocytes (Imm), after transfection with mouse Nephrin or Kirrel2 promoter GlucON clone dual-reporter

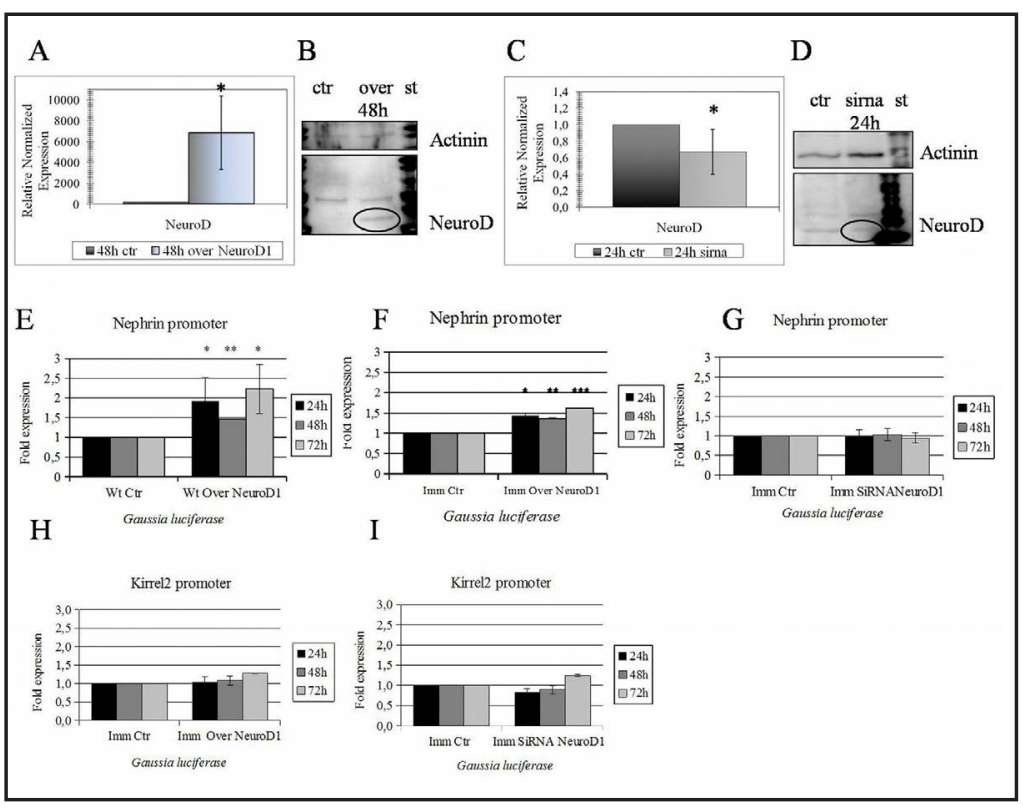
vector systems; the quantification of Gaussia luciferase bioluminescence in the surnatants was performed at 24 - 48 and 72 hours (E-FG-H-I). The values represent mean fold increase \pm SD compared to control, from at least three independent experiments performed in triplicates $\left(* \mathrm{p}<0.05,{ }^{* *} \mathrm{p}<0.01,{ }^{* * *} \mathrm{p}<0.001\right.$, Student $\mathrm{t}$ Test $)$.

\section{Regulation of NeuroD activity}

After having established the presence of NeuroD in podocytes we determined its phosphorylation status. NeuroD possesses five phosphorylation sites on serines that are involved in the regulation of its activity (Fig. 5A). We decided to focus on the NeuroD1 phosphorylation site at serine 274 (Ser274), associated with Neuro bHLH domain, since it has been demonstrated to be involved in nuclear localization in pinealocytes [27] and in the changes of its own subcellular localization in glucose activated MIN6 beta cells [28].

The WB of nuclear and cytoplasmic lysates demonstrates NeuroD phosphorylation on Ser 274 predominantly in the cytoplasmic fraction (Fig. 5B). 


\section{Cellular Physiology Cell Physiol Biochem 2018;46:873-889 \begin{tabular}{l|l} 
DOI: 10.1159/000488818 & a 2018 The Author(s). Published by S. Karger AG, Basel \\
wwww.karger.com/cpb
\end{tabular} \\ Armelloni et al.: NeuroD Expression in Podocytes and Nephrin Regulation}

Fig. 8. NeuroD induces nephrin transcription and translation. Nephrin mRNA quantification by RTqPCR and protein expression by WB were evaluated after 48 hours of NeuroD upregulation $(A ; D)$ or silencing $(B ; E)$ of differentiated podocytes, in three independent experiments; actinin or tubulin were used as loading control. Neuro2a cells were used as nephrin positive control.(D) The same quantification was also performed after NeuroD overexpression of immature podocytes (C; F) $\left({ }^{*} \mathrm{p}<0.05\right.$ Student $\mathrm{t}$ Test).

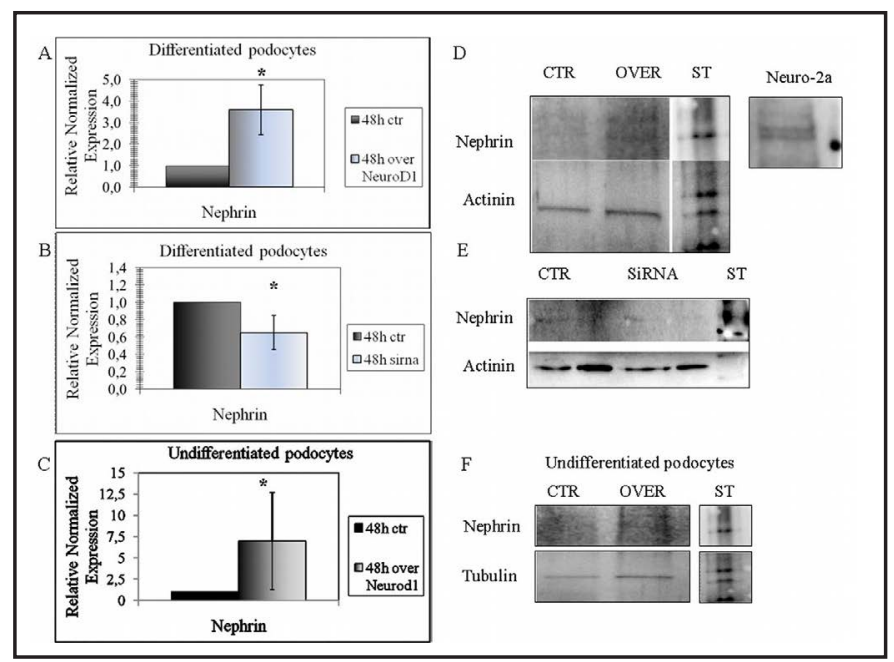

Fig. 9. NeuroD is associated to nephrin in the cytoplasm of podocytes. The role of NeuroD in the cytoplasm was investigated analysing the interactions with some proteins interacting with cytoskeleton. NeuroD binding to nephrin was detected by WB on podocytes nephrin IPs samples and on total podocytes lysates, used as control, of untreated or NeuroD overexpressed podocytes (A). Thereafter NeuroD and nephrin colocalization was assessed by IF (B) (Scale bar $50 \mu \mathrm{m}$ ).On the contrary examination by PLA demonstrates that the linking between NeuroD and slit diaphragm protein podocin (C) as well as the association with the interme-

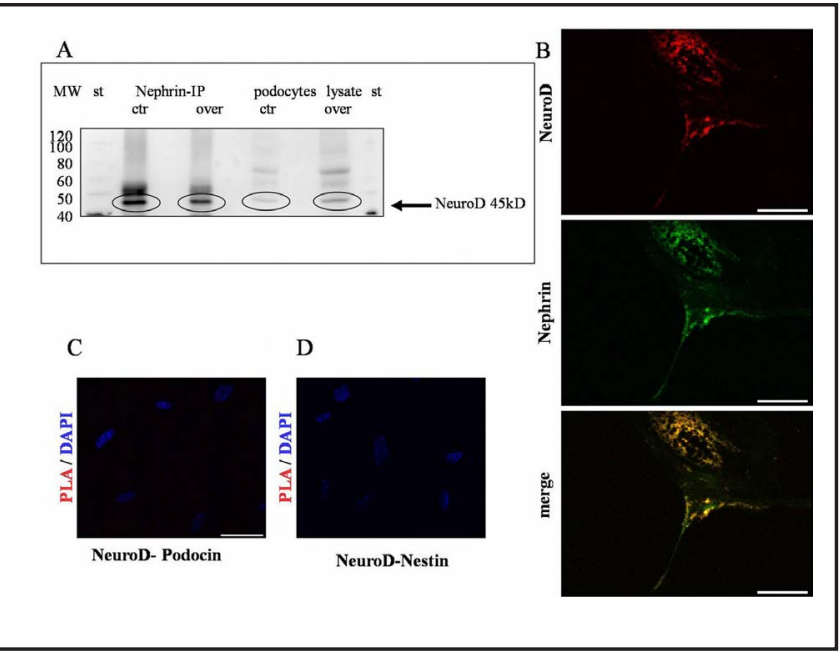
diate filament nestin (D), is absent.

\section{NeuroD binds to chromatin in the Nephrin promoter region}

Based on a preliminary research of NeuroD regulatory elements in the Nephrin promoter region (NSITE, Recognition of Regulatory motifs, Soft Berry online service), we identified a specific sequence GttGCCGGgCGACgGCTGGG for NeuroD binding (Fig. 6A). Chromatin NeuroD immunoprecipitation (ChIP assay) and PCR of Nephrin promoter confirmed a consistent link of NeuroD with the Nephrin promoter (Fig. 6B). The quantification of Nephrin promoter present in the nucleus, in relation to the quantity linked to NeuroD, demonstrates that a substantial amount, though not all the promoter, is bound to NeuroD (Fig. 6C). The estimated 468bp amplicon of Nephrin promoter seems to be located 2012 bps before the 3' side of Nephrin precursor and 1266 bp at 5' side of Kirrel2 precursor (BLAST).

\section{NeuroD affects regulation of Nephrin in podocytes}

Then we moved to evaluate the regulation of promoter activity of both Nephrin and Kirrel2 genes, which are functionally related, after NeuroD over-expression or silencing. Since we found that NeuroD mRNA maximal increase after over-expression and maximal decrease after silencing were observed at 48 and 24 hours respectively (Fig. 7A-C), we assessed at these same times the variation of NeuroD translation by $\mathrm{WB}$, demonstrating the appearance and reduction of the NeuroD band after over-expression and silencing of NeuroD gene respectively (Fig. 7B-D). 


\section{Cellular Physiology Cell Physiol Biochem 2018;46:873-889 and Biochemistry \begin{tabular}{l|l} 
DOI: 10.1159/000488818 & (c) 2018 The Author(s). Published by S. Karger AG, Basel \\
www.karger.com/cpb
\end{tabular} Armelloni et al.: NeuroD Expression in Podocytes and Nephrin Regulation}

Thereafter we examined the consequent variations in Nephrin promoter activity. In primary podocytes NeuroD overexpression was followed by a significant increase of 1.93 fold $\left({ }^{*} \mathrm{p}<0.05\right), 1.46$ fold $\left({ }^{* *} \mathrm{p}<0.01\right)$ and 2.23 fold $(* p<0.05)$ after 24 , 48 and 72 hours respectively (Fig. 7E); a similar effect was observed in SV1 cells with an up regulation of $1.43\left({ }^{*} \mathrm{p}<0.05\right), 1.36$ $\left.{ }^{* *} \mathrm{p}<0.01\right)$ and 1.62 fold $\left({ }^{* *} \mathrm{p}<\right.$ 0.001 ), respectively at $24-48$ and 72 hours (Fig. 7F).

NeuroD RNA silencing didn't influence Nephrin promoter activity at all times tested (Fig. $7 \mathrm{G}$ ). Kirrel2 promoter activity didn't undergo significant change at any time of both conditions tested (Fig. 7H-I). To examine whether the raised Nephrin promoter activity resulted in changes of its mRNA level we performed an RTqPCR. At 48 hours from transfecting NeuroD clone a significant 3.6 fold upregulation of nephrin mRNA $(* \mathrm{p}=$ 0.017 ) was observed (Fig. 8A). NeuroD transient mRNA silencing resulted in nephrin transcription reduction: after 24 hours nephrin mRNA expression decreased by 41 percent in respect to control $\left.{ }^{*} \mathrm{p}=0.022\right) \quad$ (Fig. 8B). The capacity to induce nephrin mRNA transcription was assessed also in undifferentiated podocytes after NeuroD overexpression. We found that nephrin mRNA increase was higher in undifferentiated podocytes than in the mature cells (Fig. 8C). Since NeuroD silencing or overexpression did not affect Kirrel2 promoter activity, Kirrel2 mRNA expression was not evaluated. Subsequently nephrin expression was analyzed by WB. Since variation of NeuroD synthesis into the nuclear lysate was demonstrated mainly after 48 hours, nephrin expression was evaluated at the same time (Fig. 8D-E). In fact, NeuroD overexpression resulted in a slight increase of nephrin protein only in primary podocytes but not in undifferentiated cells. A marginal reduction of nephrin protein was observed in primary podocytes after NeuroD silencing (Fig. 8F).

NeuroD is associated to Nephrin and alpha Actinin4 in the cytoplasm of podocytes

Next, the possible role of cytoplasmic NeuroD was investigated analysing the relationships with some proteins interacting with cytoskeleton. NeuroD linking with 


\section{Cellular Physiology Cell Physiol Biochem 2018;46:873-889 \begin{tabular}{l|l} 
DOI: 10.1159/000488818 & and Biochemistry 2018 The Author(s). Published by S. Karger AG, Basel \\
wuww.karger.com/cpb
\end{tabular} \\ Armelloni et al.: NeuroD Expression in Podocytes and Nephrin Regulation}

Fig. 12. Adriamycin and NeuroD over-expression effects on NeuroD, actinin4 and nephrin distribution and on foot processes length. IF staining of NeuroD (A) (scale bar $100 \mu \mathrm{m}$ ), Ac-

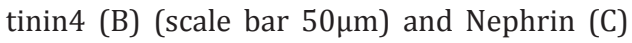
(scale bar $100 \mu \mathrm{m}$ ) was performed in different conditions: control, NeuroD overexpression, adriamycin damage, adriamycin followed by NeuroD overexpression. Measure of podocytes foot processes extension was calculated on actinin4 images after acquisition.(scale bar $50 \mu \mathrm{m})$.(D) Processes length was measured in control and differently treated podocytes. After NeuroD overexpression the length doesn't significantly change; after adriamycin the cell damage induces decrease of processes length $\left({ }^{*} \mathrm{p}<0.05\right)$; the transfection with NeuroD clone of podocytes previously treated with adriamycin leads to significant elongation of the cell processes $(* \mathrm{p}=0.02)$.

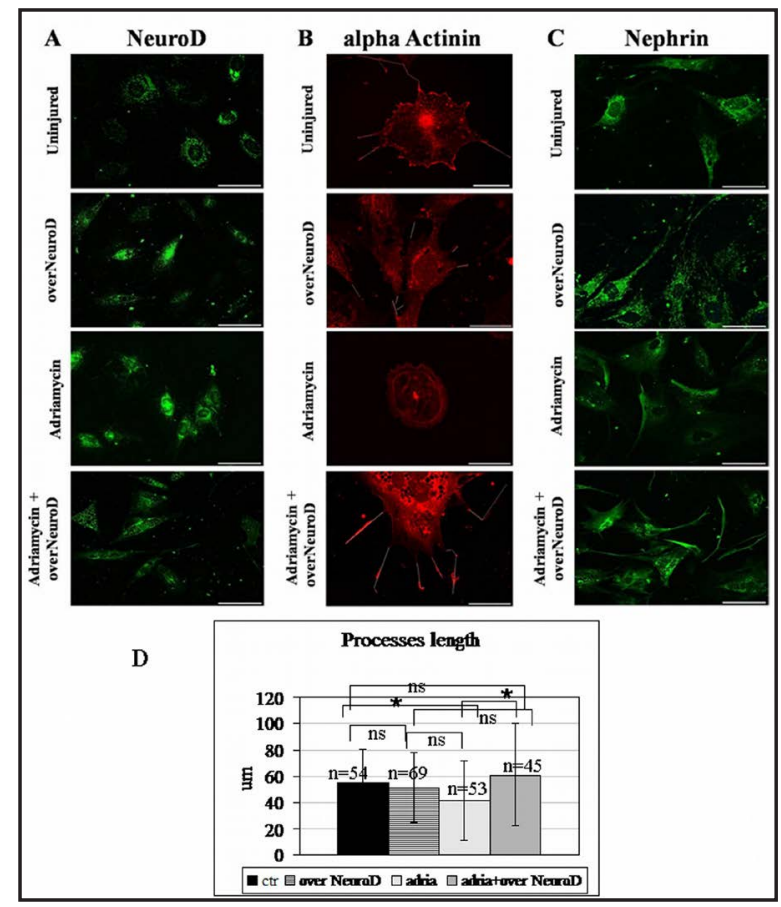

nephrin was demonstrated, by checking with WB for NeuroD presence, in samples obtained by nephrin-immunoprecipitated cytoplasmic lysates (the upper $50 \mathrm{kD}$ band represents the $\mathrm{H}$ chain of the antibody used to immunoprecipitate) (Fig. 9A). The close link between NeuroD and nephrin interaction was further verified by the positivity of IF colocalization staining (Fig. 9B), while no association with podocin and nestin was found by PLA (Fig. 9C-D).

Finally we also checked for NeuroD interaction with another key cytoskeleton protein, alpha actinin4. In fact we found, with WB analysis, a clear band referable to actinin4 in the NeuroD, immunoprecipitated cytoplasmic lysate obtained from NeuroD over-expressing podocytes, whereas no actinin 4 was evident in the control sample (Fig. 10A). On the other hand, the close proximity of NeuroD and actinin4 at both PLA (Fig. 10B) and IF colocalization analyses (Fig. 10C) highly suggested their co-expression both in the control and in the overexpressing conditions.

Podocytes foot processes injury after adriamycin was partially restored by NeuroD overexpression

Then we focussed on the effects of cytoskeleton injury on NeuroD (Fig. 11); in mouse cultured podocytes injured by adriamycin addition, NeuroD is mainly distributed into the nucleus (Fig. 11A).The NeuroD staining of kidney section obtained from mouse model of adriamycin nephropathy and from human biopsy of patients with diabetes seems impaired (Fig. 11 B-C);

Thereafter we also evaluated, in cultured podocytes, whether NeuroD over-expression may have any effect on the entity of cell damage evaluated by cell shape modifications, after adriamycin exposure (Fig. 12). As already known, adriamycin treatment induces marked cell shape changes, due to cytoskeleton damage, with a shortening of podocytes foot processes (Fig. 12 B-D) and a redistribution of nephrin (Fig. 12C). NeuroD over-expression in control cells, though associated with an increased nuclear IF positivity didn't result in any cell shape modification as compared with normal control cells (Fig. 12B-D). Over-expression of NeuroD in adriamycin treated cells shows a trend of cell processes to elongate, as compared with cells treated with only adriamycin (Fig. 12B-C-D). 


\section{Cellular Physiology Cell Physiol Biochem 2018;46:873-889

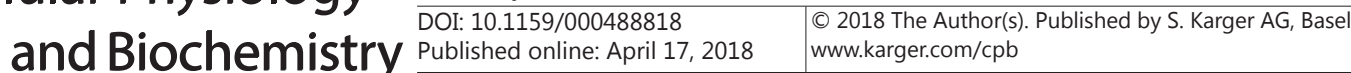 \\ Armelloni et al.: NeuroD Expression in Podocytes and Nephrin Regulation}

\section{Discussion}

Podocytes have long been considered advanced cells similar to neurons in account of their highly ramified primary and secondary processes and of the common expression of signalling, receptors and cytoskeletal proteins; the control of glomerular filtration, with such sophisticated neuron-like machinery, is mainly localized in the slit diaphragm junction $[8,11,29-33]$. Previous studies have shown that some neuronal TFs are expressed also in podocytes, such as Kreisler (MafB) which is involved in both early central nervous system organization and in kidney development [34], regulating also Nephrin promoter activity [35]. NeuroD, a member of helix-loop-helix (bHLH) transcription factor, is a potent regulator of neuron differentiation and survival both at an early and late stage of the central nervous system (CNS) development [36, 37], and genetic mutations of NeuroD gene are associated with severe abnormalities of many neurological functions [38-40].

Since it has been long known that NeuroD controls dendrite development in neurons, we first looked for the presence of this TF also in podocytes and, if the case, for its potential role in the control of foot process behaviour, in a model of cytoskeleton injury (adriamycin nephropathy) [41].

First, we mainly focussed on NeuroD localization in human and mice glomeruli. In fact, we observed NeuroD distribution almost exclusively in podocytes, and not in the other glomerular cells (endothelial and mesangial cells).

Consequently, we studied more in depth the NeuroD distribution in podocytes, demonstrating that NeuroD is localized both in the nucleus and unexpectedly also in the cytoplasm, where it is diffused not only in the endoplasmic reticulum but also along the foot processes. The main NeuroD band observed with WB, independently of the antibody used, was of about $40 \mathrm{kD}$ which is the known molecular weight of the intact molecule; however, two additional bands with consistently higher MW were evident, but only when the antibodies recognising the $\mathrm{C}$ or $\mathrm{N}$-terminal epitopes were used. One of these bands is compatible with the molecular weight of a dimeric complex of the NeuroD molecule, as it has been reported also in CNS, where the dimers have been suggested to act on a specific consensus sequence of the DNA E-box region [42].. However, it is not easy to explain why this band is not evident when the antibody directed towards the intermediate portion of the NeuroD region was used. Alternatively our findings could suggest that some molecules with variable MW, not completely detached by the experimental treatments, might bind the intermediate portion of NeuroD molecule, preventing the binding of the antibody specifically directed to the epitopes present in this region. These putative molecules could be functionally associated to NeuroD, as observed in CNS where different and tissue related cofactors interact with the proneural proteins and are responsible for the specific and cellular context related gene activation and can modulate the transcription activity $[17,42]$. Of course, these interesting aspects need more in depth investigations.

When we explored the NeuroD expression at different times of podocyte maturation, we found that both mRNA and protein expression was evident in the undifferentiated and differentiated podocytes. However, mature cells expressed the molecule at a relevant higher level than immature podocytes; furthermore, NeuroD staining in the differentiated cells was more marked in the nuclear compartment. The role of NeuroD at these different stages of podocyte development could be different, possibly involved in cell differentiation in the early stage and in the development and maintenance of cell functionality (foot processes development and repair?) at the latest stages: this issue is worthy of future investigations.

Since it is known that phosphorylation status of NeuroD affects its functionality in neurons and in non neuronal cells, and that the modification of the same residues of NeuroD can have opposite regulatory effects in different cells types [19, 43, 44] we assessed in podocytes NeuroD phosphorylation of one of the four known phosphorylation sites of NeuroD, the predominant site for ERK2 activity (serine274) [44].

Our preliminary results confirm NeuroD phosphorylation on serine274, in immature and in differentiated podocytes, even if marked differences were observed, suggesting 
a variability among cultured cells. Furthermore, we were not able to demonstrate any NeuroD phosphorylation in the nuclear compartment. These findings might suggest that in the nucleus the activation of the protein could be mediated by dephosphorylation or it is likewise reasonable that only the not-phosphorylated molecule could migrate into the nucleus and that the phosphorylation status in the cytoplasm might be the controlling pathway of nuclear transport. Alternatively (or additionally) it can be supposed that post translational modification mechanism(s), such as the phosphorylation, induces some additional activities involved in specific cytoplasmic metabolic pathways $[28,44,45]$. In this way, the phosphorylation process of NeuroD might control its activity at both the nuclear and cytoplasmic levels.

Successively to support the hypothesis of some involvement of NeuroD in podocytes differentiation we studied the DNA associated role and looked in online database for a specific sequence for NeuroD in the Nephrin promoter region; by ChIP assay and by subsequently PCR, we found that NeuroD binds to the Nephrin promoter in podocytes and its over expression results in an increased activity of the promoter gene. On the other hand, NeuroD silencing does not induce any change in the Nephrin promoter activity. These results could suggest that in stress condition, the cells need more NeuroD for inducing structural protein synthesis. Alternatively, as described in CNS where several TFs act redundantly to securely control neuronal differentiation, [17] we could also assume that other TFs contribute to the persistence of the promoter activity. As far as the effects of NeuroD over-expression and silencing on nephrin transcription and protein production is concerned, we found that these experimental conditions translated into an increase and a decrease respectively of both nephrin mRNA and protein, highlighting the importance of NeuroD on nephrin regulation. The effect on nephrin transcription resulted particularly evident in the undifferentiated podocytes. This might suggest the need for higher protein synthesis, not yet present in the immature podocytes, for inducing contact with neighbouring cells and filtration selectivity. However, the effect on mRNA was not paralleled by a conspicuous and detectable amount on nephrin protein. If post transcriptional or translational changes are responsible for these findings it is worthy of further studies.

Since it is known that Kirrel2 and Nephrin are bidirectional gene pairs [4, 5, 7, 46], we looked for a possible comparable behaviour of these genes secondary to NeuroD activation or repression. In fact, we were not able to demonstrate any major variation in Kirrel2 activity following either NeuroD over-expression or silencing. This discrepancy is not clear, we can only hypothesize that NeuroD binding is on the plus-strand of promoter gene of Nephrin, while on the minus- strand of the Kirrel2 promoter, with the first effects being much more detectable than the second one.

The findings reported above are mainly directed to describe the potential role of nuclear NeuroD, but the possible function of the cytoplasmic fraction is even more unclear.

It is already known that other TFs, expressed both in nucleus and cytoplasm of various cell type, are able to exert additional control in respect to canonical transcriptional gene regulation. For example, Emx2, NRSF, MIZ-1, Bach1 and other TFs have different binding domains, some specific for DNA, others for RNA or for proteins. Their function is different when they are expressed in the nucleus and in the cytoplasm where they enhance post transcriptional or translational regulation or remain anchored to the cytoskeleton $[47,48]$.. NeuroD mediation of events taking place in cytoplasm has been reported in CNS, with the task of specifying axonal and dendritic growth and by modulating dendritic spine stability and morphology [19].

Therefore looking further into the parallelism between podocytes and neurons, we focused on some morphological and functional aspects of NeuroD present in the cytoplasm of podocytes along the membrane and the foot processes. We previously showed that another neuropeptide, BDNF, determines an actin-inducing effect on podocytes cytoskeleton after damage [16]. In the present work we observed a close linking between NeuroD and nephrin and between NeuroD and actinin4 (in fact we found a close co-expression of NeuroD and nephrin in both normal condition and after NeuroD up-regulation and a co-expression of

\section{KARGER}




\section{Cellular Physiology Cell Physiol Biochem 2018;46:873-889

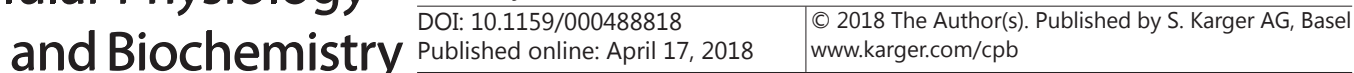 \\ Armelloni et al.: NeuroD Expression in Podocytes and Nephrin Regulation}

NeuroD and actinin4 fully evident after NeuroD over-expression). To understand the possible implications these associations in pathological conditions could have, we explored, in an already well studied model of podocyte injury (adriamycin)[41, 49], whether the damage itself could alter NeuroD distribution in the cells and/or the changes in NeuroD expression might influence the extent of the cell damage in podocyte cytoskeleton.

As is well known, adriamycin modifies actin filaments distribution and processes extension in podocytes; the repair needs a reorganization by inducing gene expression and by changing actin dynamic, in which numerous adaptor and effector proteins take part [16]. Actin filaments are composed of bundles of filaments cross linked by the actin binding-protein alpha actinin4 that collaborates, with others filament associated proteins, in regulating the stability of the podocytes. Alpha actinin4 is essential for the signalling from the extracellular compartment to the cytoskeleton for inducing its reorganization and maintaining podocyte function. This signalling pathway happens through and interaction of alpha actinin 4 with kinases and membrane signalling proteins $[8,50,51]$ like nephrin. We observed that adriamycin treatment induces NeuroD increase in the nuclear compartment. NeuroD over expression in control cells causes, as expected, nuclear and cytoplasmic increase but nobody associated visible cell shape change or processes length variation. Only when NeuroD over-expression greatly enhances NeuroD accumulation in previously adriamycin treated podocytes, concomitant important mechanisms of repair in podocytes shape take place. These results suggest that cell damage caused by adriamycin leads to NeuroD increase and triggers the processes of recovery.

We speculate that possibly NeuroD supports actinin 4 and nephrin adaptor function regulating podocytes shape integrity, and this should account for the observed proximity between these three molecules.

Far from understanding all the precise roles that NeuroD plays in the kidney our work shows that NeuroD is involved in Nephrin gene activation and in protein synthesis and contributes to podocytes cytoskeletal dynamics in response to injury. The results provide a stimulus to investigate in new directions to identify additional functions associated to molecules primarily involved in podocytes regulatory system.

\section{Acknowledgements}

The work was supported by funding from IRCCS Ospedale Maggiore Policlinico, Milan. All authors have reviewed the results and approved the final version of the manuscript.

\section{Disclosure Statement} article.

The authors declare that they have no conflicts of interest with the contents of this

\section{References}

1 Drenckhahn D, Franke RP: Ultrastructural organization of contractile and cytoskeletal proteins in glomerular podocytes of chicken, rat and man. Lab Invest 1988;59:673-682.

-2 Mundel P and Shankland SJ: Podocyte Biology and Response to Injury. J Am Soc Nephrol 2002;13:30053015.

-3 Quaggin SE: Transcriptional Regulation of Podocyte Specification and Differentiation. Microsc Res Tech 2002;57:208-211.

4 Beltcheva O, Hjorleifsdottir EE, Kontusaari S, Tryggvason K: Sp1 Specifically Binds to an Evolutionarily Conserved DNA Segment within a Region Necessary for Podocyte-Specific Expression of Nephrin. Nephron Exp Nephrol 2010;114:e15-e22. 


\section{Cellular Physiology Cell Physiol Biochem 2018;46:873-889 \begin{tabular}{l|l} 
and Biochemistry Published online: April 17, 2018 & $\begin{array}{l}\text { D) } 2018 \text { The Author(s). Published by S. Karger AG, Basel } \\
\text { www.karger.com/cpb }\end{array}$
\end{tabular} \\ Armelloni et al.: NeuroD Expression in Podocytes and Nephrin Regulation}

5 Ristola M, Arpiainen S, Saleem MA, Mathieson PW, Welsh GI, Lehtonen S, Holthöfer H: Regulation of Neph3 gene in podocytes-key roles of transcription factors NFkB and SpI. BMC Mol Biol 2009;10:83.

-6 Ristola M, Arpiainen S, Shimokawa T, Ra C, Tienari J, Saleem MA, Holthöfer H, Lehtonen S: Regulation of nephrin gene by the Ets transcription factor, GA-binding protein. Nephrol Dial Transplant 2013;28:846855.

7 Ristola M and Lehtonen S: Functions of the podocyte proteins nephrin and Neph3 and the transcriptional regulation of their genes. Clinic Sci 2014;126:315-328.

-8 Rastaldi MP, Armelloni S, Berra S, Li M, Pesaresi M, Poczewski H, Langer B, Kerjaschki D, Henger AS, Blattner M, Kretzler M, Wanke R and D’Amico G: Glomerular Podocytes Possess the Synaptic Vesicle Molecule Rab3A and Its Specific Effector Rabphilin-3a. Am J Pathol 2003;163:889-899.

-9 Kobayashi N, Gao SY, Chen J Saito K, Miyawaki K, Li CY, Pan L, Saito S, Terashita T, Matsuda S: Process formation of the renal glomerular podocyte: is there common molecular machinery for processes of podocytes and neurons? Anat Sci Int 2004;79:1-10.

10 Reiser J, Polu KR, Moller CC, Kenlan P, Altintas MM, Wei C, Faul C, Herbert S, Villegas I, Avila-Casado C, McGee M, Sugimoto H, Brown D, Kalluri R, Mundel P, Smith PL, Clapham DE, Pollak MR: TRPC6 is a glomerular slit diaphragm-associated channel required for normal renal function. Nat Genet 2005;37:739744.

11 Rastaldi MP, Armelloni S, Berra S, Calvaresi N, Corbelli A, Giardino LA, Li M, Wang GQ, Fornasieri A, Villa A, Heikkila E, Soliymani R, Boucherot A, Cohen CD, Kretzler M, Nitsche A, Ripamonti M, Malgaroli A, Pesaresi M, Forloni GL, Schlondorff D, Holthofer H, D’Amico G: Glomerular podocytes contain neuron-like functional synaptic vesicles. FASEB J 2006;20:976-978.

12 Giardino L, Armelloni S, Corbelli A, Mattinzoli D, Zennaro C, Guerrot D, Tourrel F, Ikehata M, Li M, Berra S, Carraro M, Messa P, Rastaldi MP: Podocyte glutamatergic signaling contributes to the function of the glomerular filtration barrier. J Am Soc Nephrol 2009;20:1929-1940.

-13 Puliti A, Rossi PI, Caridi G, Corbelli A, Ikehata M, Armelloni S, Li M, Zennaro C, Conti V, Vaccari CM, Cassanello M, Calevo MG, Emionite L, Ravazzolo R, Rastaldi MP: Albuminuria and glomerular damage in mice lacking the metabotropic glutamate receptor 1 Am J Pathol 2011;178:1257-1269

14 Li M, Armelloni S, Ikehata M, Corbelli A, Pesaresi M, Calvary N, Giardino L, Mattinzoli D, Nisticò F, Andreoni S, Puliti A, Ravazzolo R, Forloni G, Messa P, Rastaldi MP: Nephrin expression in adult rodent central nervous system and its interaction with glutamate receptors. J Pathol 2011;225:118-128.

15 Endlich N, Kress KR, Reiser J, Uttenweiler D, Kriz W, Mundel P, Endlich K: Podocytes Respond to Mechanical Stress In vitro. J Am Soc Nephrol 2001;12:413-422.

-16 Li M, Armelloni S, Zennaro C, Wei C, Corbelli A, Ikehata M, Berra S, Giardino L, Mattinzoli D, Watanabe S, Agostoni C, Edefonti A, Reiser J, Messa P, Rastaldi MP: BDNF repairs podocyte damage by microRNAmediated increase of actin polymerization. J Pathol 2015;235:731-744.

17 Seo S, Lim JW, Yellajoshyula D, Chang LW, Kroll KL: Neurogenin and NeuroD direct transcriptional targets and their regulatory enhancers. EMBO J 2007;26:5093-5108.

18 Ma Q, Kintner C and Anderson DJ: Identification of neurogenin, a vertebrate neuronal determination gene. Cell 1996;87:43-52.

19 Gaudillière B, Konishi Y, de la Iglesia N, Yao GI, Bonni A: A CaMKII NeuroD Signaling Pathway Specifies Dendritic Morphogenesis. Neuron 2004;41:229-241.

20 Zheng H, Zeng Y, Chu J, Kam AY, Loh HH, Law PY: Modulations of NeuroD activity contribute to the differential effects of morphine and fentanyl on dendritic spine stability. I Neurosci 2010;30:8102-8110.

-21 Calella AM, Nerlov C, Lopez RG, Sciarretta C, von Bohlen und Halbach O, Bereshchenko O, Minichiello L: Neurotrophin/Trk receptor signaling mediates $C / E B P \alpha,-\beta$ and NeuroD recruitment to immediate-early gene promoters in neuronal cells and requires $\mathrm{C} / \mathrm{EBP}$ s to induce immediate-early gene transcription. Neural Dev 2007;2:4.

22 Naya FJ, Stellrecht CM, Tsai MJ: Tissue-specific regulation of the insulin gene by a novel basic helix-loophelix transcription factor. Gen Dev 1995;9:1009-1019.

23 Ito T, Udaka N, Yazawa T, Okudela K, Hayashi H, Sudo T, Guillemot F, Kageyama R, Kitamura H: Basic helixloop-helix transcription factors regulate the neuroendocrine differentiation of fetal mouse pulmonary epithelium. Development 2000;127:3913-3921.

24 Naya FJ, Huang HP, Qiu Y: Diabetes, defective pancreatic morphogenesis, and abnormal enteroendocrine differentiation in BETA2/neuroD-deficient mice. Genes Dev 1997;11:2323-2334.

25 Maezawa Y, Onay T, Scott RP, Keir LS, Dimke H, Li C, Eremina V, Maezawa Y, Jeansson M, Shan J, Binnie M, Lewin M, Ghosh A, Miner JH, Vainio SJ, Quaggin SE:Loss of the Podocyte-Expressed Transcription Factor Tcf21/Pod1 Results in Podocyte Differentiation Defects and FSGS. J Am Soc Nephrol 2014;25:2459-2470. 


\section{Cellular Physiology Cell Physiol Biochem 2018;46:873-889 \begin{tabular}{l|l} 
and Biochemistry Published online: April 17, 2018 & $\begin{array}{l}\text { D) } 2018 \text { The Author(s). Published by S. Karger AG, Basel } \\
\text { www.karger.com/cpb }\end{array}$
\end{tabular} \\ Armelloni et al.: NeuroD Expression in Podocytes and Nephrin Regulation}

-26 Kizuka Y, Kitazume S, Okahara K, Villagra A, Sotomayor EM and Taniguchi N: Epigenetic Regulation of a Brain-specific Glycosyltransferase $N$-Acetylglucosaminyltransferase-IX (GnT-IX) by Specific Chromatin Modifiers. J Biol Chem 2014;289:11253-11261.

-27 Castro AE, Benitez SG, Farias Altamirano LE, Savastano LE, Patterson SI, Muñoz EM: Expression and cellular localization of the transcription factor NeuroD1 in the developing and adult rat pineal gland. J Pineal Res 2015;58:439-451.

28 Petersen HV, Jensen JN, Stein R, and Serup P: Glucose induced MAPK signalling influences NeuroDmediated activation and nuclear localization. FEBS Lett 2002;528:241-245.

29 Mundel P, Heid HW, Mundel M, Kruger M, Reiser J, Kriz W: Synaptopodin: an actin-associated protein in telencephalic dendrites and renal podocytes. J Cell Biol 1997;139:193-204.

-30 Putaala H, Soininen R, Kilpelainen P, Wartiovaara J, Tryggvason K: The murine nephrin gene is specifically expressed in kidney, brain and pancreas: inactivation of the gene leads to massive proteinuria and neonatal death. Hum Mol Genet 2001;10:1-8.

31 Faul C, Asanuma K, Yanagida-Asanuma E, Kim K, Mundel P: Actin up: regulation of podocyte structure and function by components of the actin cytoskeleton. Trends Cell Biol 2007;17:428-437.

-32 Armelloni S, Corbelli A, Giardino L, Li M, Ikehata M, Mattinzoli D, Messa P, Pignatari C, Watanabe S, Rastaldi MP: Biomol. Concepts. Podocytes: recent biomolecular developments. Biomol Concepts 2014;5:319-330.

33 Fukusumi Y, Miyauchi N, Hashimoto T, Saito A, Kawachi H: Therapeutic target nephrotic syndrome: identification of novel slit diaphragm associated molecules. World J Nephrol 2014;3:77-84. Kreidberg JA: Podocyte Differentiation and Glomerulogenesis. J Am Soc Nephrol 2003;14:806-814. Morito N, Yoh K, Ojima M, Okamura M, Nakamura Mamada M, Shimohata H, Moriguchi T, Yamagata K, Takahashi S: Overexpression of Mafb in podocytes protects against diabetic nephropathy. J Am Soc Nephrol 2014;25:2546-2557.

-36 Lee JE: Basic helix-loop-helix genes in neural development. Curr Opin Neurobiol 1997;7:13-20.

-37 Schwab MH, Bartholomae A, Heimrich B, Feldmeyer D, Druffel-Augustin S, Goebbels S, Naya FJ, Zhao S, Frotscher M, Tsai MJ, Nave KA: Neuronal Basic Helix-Loop-Helix Proteins (NEX and BETA2/Neuro D) Regulate Terminal Granule Cell Differentiation in the Hippocampus. J Neurosci 2000;20:3714-3724.

38 Miyata T, Maeda T, Lee JE: NeuroD is required for the differentiation of the granule cells in the cerebellum and hippocampus. Genes Dev 1999;13:1647-1652.

-39 Liu M, Pleasure SJ, Collins AE, Noebels JL, Naya FJ, Tsai MJ, Lowenstein DH: Loss of BETA2/NeuroD leads to malformation of the dentate gyrus and epilepsy. Proc Natl Acad Sci U S A 2000;97:865-870.

40 Kim WY, Fritzsch B, Serls A, Bakel LA, Huang EJ, Reichardt LF, Barth DS, Lee JE: NeuroD-null mice are deaf due to a severe loss of the inner ear sensory neurons during development. Development 2001;128:417426.

41 Lee VW, Harris DC: Adriamycin nephropathy: a model of focal segmental glomerulosclerosis. Nephrology (Carlton) 2011;16: 30-38.

42 Bertrand N, Castro DS, Guillemot F: Proneural genes and the specification of neural cell types. Nat Rev Neurosci 2002;3:517-530.

43 Dufton C, Marcora E, Chae JH, McCullough J, Eby J, Hausburg M, Stein GH, Khoo S, Cobb MH, Lee JE: Contextdependent regulation of NeuroD activity and protein accumulation. Mol Cell Neurosci 2004;28:727-736.

44 Khoo S, Griffen S, Xia Y, Baer R J, German MS and Cobb MH: Regulation of insulin gene transcription by ERK1 and ERK2 in pancreatic beta cells. J Biol Chem 2003;278:32969-32977.

-45 Nardozzi JD, Lott K, Cingolani G:Phosphorylation meets nuclear import: a review. Cell Commun Signal 2010;8:32.

46 Guo G, Morrison DJ, Licht JD, Quaggin SE: WT1 Activates a Glomerular-Specific Enhancer Identified from the Human Nephrin Gene. J Am Soc Nephrol 2004;15:2851-2856.

47 Cassiday L, Maher LJ 3r:Having it both ways: transcription factors that bind DNA and RNA. Nucleic Acids Res 2002;30:4118-4126.

48 Ziegelbauer J, Shan B, Yager D, Larabell C, Hoffmann B, Tjian R: Transcription Factor MIZ-1 Is Regulated via Microtubule Association. Mol Cell 2001;8:339-349.

49 Zennaro C, Mariotti M, Carraro M, Pasqualetti S, Corbelli A, Armelloni S, Li M, Ikehata M, Clai M, Artero M, Messa P, Boscutti G, Rastaldi MP: Podocyte Developmental Defects Caused by Adriamycin in Zebrafish Embryos and Larvae: A Novel Model of Glomerular Damage. PLoS One 2014;9:e98131.

50 Lehtonen S, Ryan JJ, Kudlicka K, Iino N, Zhou H, Farquhar MG : Cell junction-associated proteins IQGAP1,MAGI-2,CASK, spectrins, and alpha-actinin are components of the nephrin multiprotein complex. Proc Natl Acad Sci U S A 2005;102:9814-9819.

51 Vallenius T, Luukko K, Mäkelä:TPCLP-36 PDZ-LIM protein associates with non muscle alpha-actinin-4. J Biol Chem 2000;275:11100-11151. 